\title{
Brown tumor of the palate as first manifestation of primary hyperparathyroidism: a case report
}

\author{
Bassima Chami $i^{1}{ }^{*}$, Latifa Benrachadi ${ }^{2}$, Naoual El Omri ${ }^{3}$, Mohamed El Qatni ${ }^{3}$, \\ Wafaa El Wady ${ }^{1}$, Bouabid El Mohtarim ${ }^{2}$ \\ ${ }^{1}$ Department of Oral Surgery, Faculty of Dental Medicine, Mohamed V-Souissi University, Rabat, Morocco \\ 2 Department of Odontology, Mohamed V Military Teaching Hospital, Mohammed V-Souissi University, Rabat, Morocco \\ ${ }^{3}$ Department of Internal Medicine, Mohammed V Military Teaching Hospital, Mohammed V-Souissi University, Rabat, Morocco
}

(Reçu le 16 septembre 2011, accepté le 3 octobre 2011)

Key words: brown tumor / primary hyperparathyroidism / palatal swelling

Mots clés : tumeur brune / hyperparathyroïdisme primaire / tuméfaction palatine

\begin{abstract}
Brown tumor is one of the lesions that develop in patients with hyperparathyroidism. Skeletal bones including maxillo-facial ones can be the site of this lesion. Owing to the improve methods of blood analysis most of cases of primary hyperparathyroidism are diagnosed early and asymptomatically making advanced disease with bone lesions extremely rare. This article contains a case of a 43-year-old female patient who presented with palatal swelling as the first sign of primary hyperparathyroidism. The diagnosis was suggested by the histological findings and confirmed by the endocrinologic status.
\end{abstract}

Résumé - Tumeur brune du palais comme première manifestation d'un hyperparathyroïdisme primaire. Présentation d'un cas. La tumeur brune représente une des lésions que l'on peut observer dans l'hyperparathyroïdisme. Elle touche les os, y compris ceux de la région maxillo-faciale. Le bilan biologique permet de diagnostiquer la plupart des cas d'hyperparathyroïdisme primaire à un stade précoce; les formes évoluées asymptomatiques sont extrémement rares. Cet article présente un cas d'hyperparathyroïdisme primaire, chez une femme de 43 ans, où la première manifestation était constituée par une tuméfaction palatine. Le diagnostic a été évoqué à l'examen histologique et confirmé par le bilan endocrinien.
Primary hyperparathyroidism refers to the inappropriate or unregulated overproduction of parathyroid hormone leading to abnormal calcium homeostasis [1]. It is the third most common endocrine disorder after diabetes mellitus and thyroid dysfunction [2]. It is caused by parathyroid adenoma $(81 \%)$, hyperplasia $(15 \%)$ or carcinoma $(0.5-4 \%)$ [3]. Most cases of primary hyperparathyroidism are identified by hypercalcemia and hypophosphatemia on routine serum testing $[3,4]$. Cases recognized by the presence of brown tumors are uncommon [4]. In this paper we report a case, of a large swelling in the palate corresponding to a maxillary brown tumor related to primary hyperparathyroidism, whitch is an unusual first manifestation of the disease.

\section{Case report}

A 43-year-old woman patient presented with a swelling in the anterior right region of the palate since 6 months. Extraoral examination revealed a swelling in the right middle third of the face (Fig. 1A). Intraoral examination a large palatal swelling measuring around $4 \times 3 \mathrm{~cm}$ extending from the right premolar region to the left incisive region (Fig. 1B). Panoramic radiograph revealed an anterior radiolucency (Fig. 2A). Computed tomography scan showed a palatal destructive bone lesion extending to the floor of nasal cavity and expanding the cortical plate (Figs. 2B and 2C).

Incisionnal biopsy was made. Histopathological examination showed proliferation of multinucleated giant cells mixed

\footnotetext{
*Correspondence : bassima.chami1@gmail.com
} 

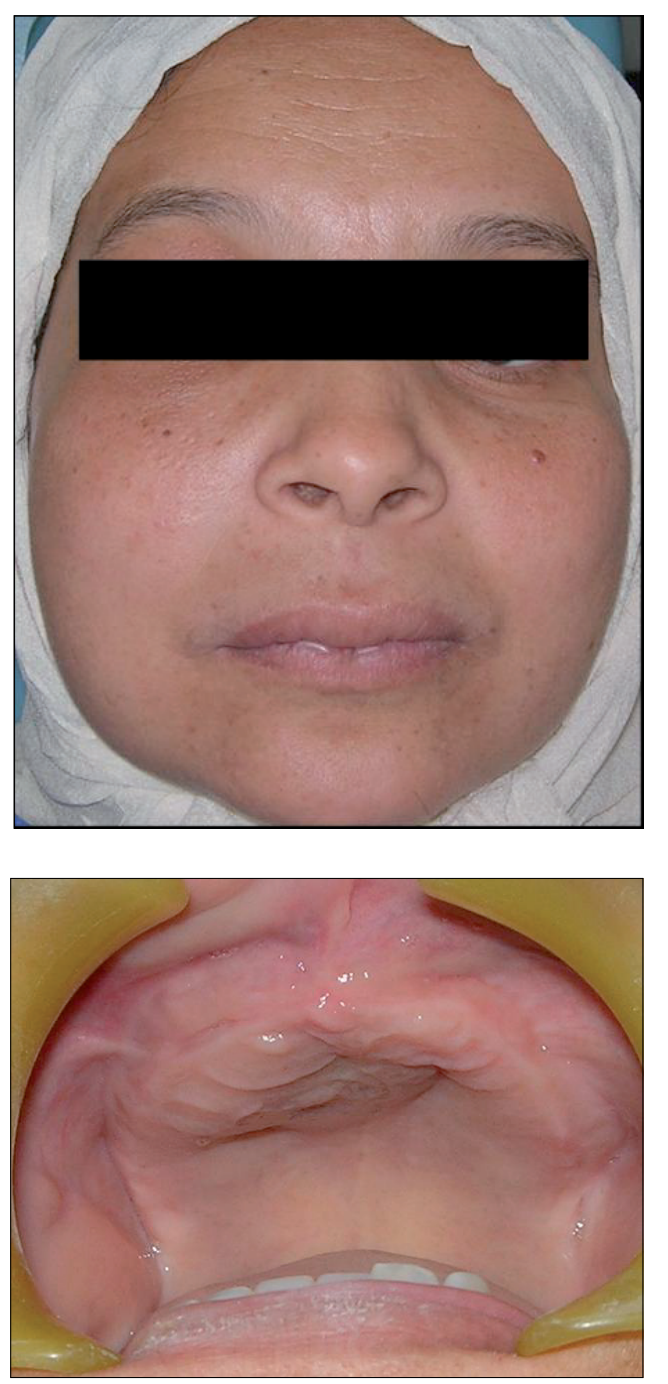

Fig. 1. (A) Extrabuccal view: facial asymmetry. (B) Intrabuccal view: well circumscribed mass on the palate.

Fig. 1. (A) Vue extra-buccale: asymétrie faciale. (B) Vue intrabuccale : tumefaction palatine bien circonscrite.

with mononuclear spindle shaped cells indicative of giant cell lesion (Fig. 3). Blood analysis revealed an elevated serum calcium $148 \mathrm{mg}^{-1}$ (normal: 86-105), decreased serum phosphorus: $17 \mathrm{mg.l}^{-1}$ (normal: 25-50), elevated parathyroid hormone level (PTH: 8608 pg. $\mathrm{ml}^{-1}$; normal: 9-55) and elevated bone densitometry. These findings suggested the diagnosis of hyercalcemia and hyperparathyroidism.

Ultrasound and computed tomography scan of the neck showed a large mass in the left lower lobe of thyroid gland measuring about $3.5 \times 1.7 \mathrm{~cm}$ (Figs. $4 \mathrm{~A}$ and $4 \mathrm{~B}$ ). There were no renal stones on the abdominal ultrasonography. The diagnosis of primary hyperparathyroidism is confirmed. Other bones lesions related to hyperparathyroidism have been showed in the skull and phalanges (Figs. 5A and 5B).
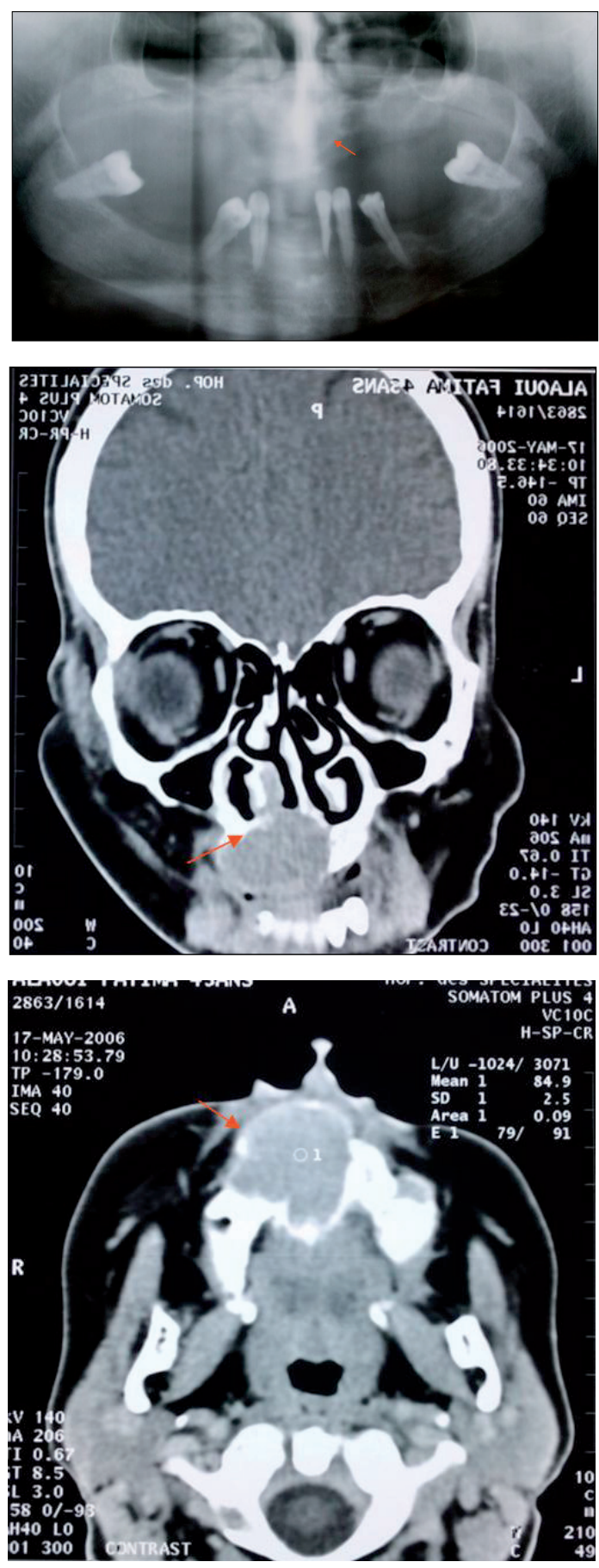

Fig. 2. (A) Panoramic radiograph: radiolucency in the anterior of the maxillary (arrow). (B) Coronal computed tomography scan showing a lytic bone lesion extending to the floor of nasal cavity (arrow). (C) Axial computed tomography scan showing the expansion of cortical bones (arrow).

Fig. 2. (A) Radiographie panoramique : radiotransparence maxillaire antérieure (fléche). (B) CT-scan : coupe coronale montrant une ostéolyse s'étendant vers le plancher des fosses nasales (fléche). (C) CTscan : coupe axiale montrant une soufflure de la corticale (fléche). 


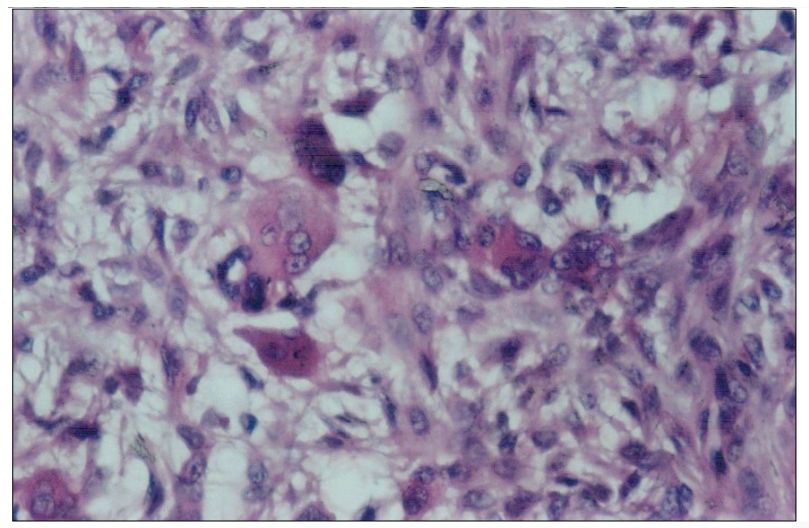

Fig. 3. Microscopic view of the palatine tumour showing proliferation of multinucleated giant cells and mononuclear spindle shaped cells (hematoxylin-eosin, magnification $\times 40$ ).

Fig. 3. Aspect microscopique de la tuméfaction palatine : proliferation de cellules géantes multinucléées et de cellules fusiformes mononucléées (hématoxyline-éosine, grossissement $\times 40$ ).
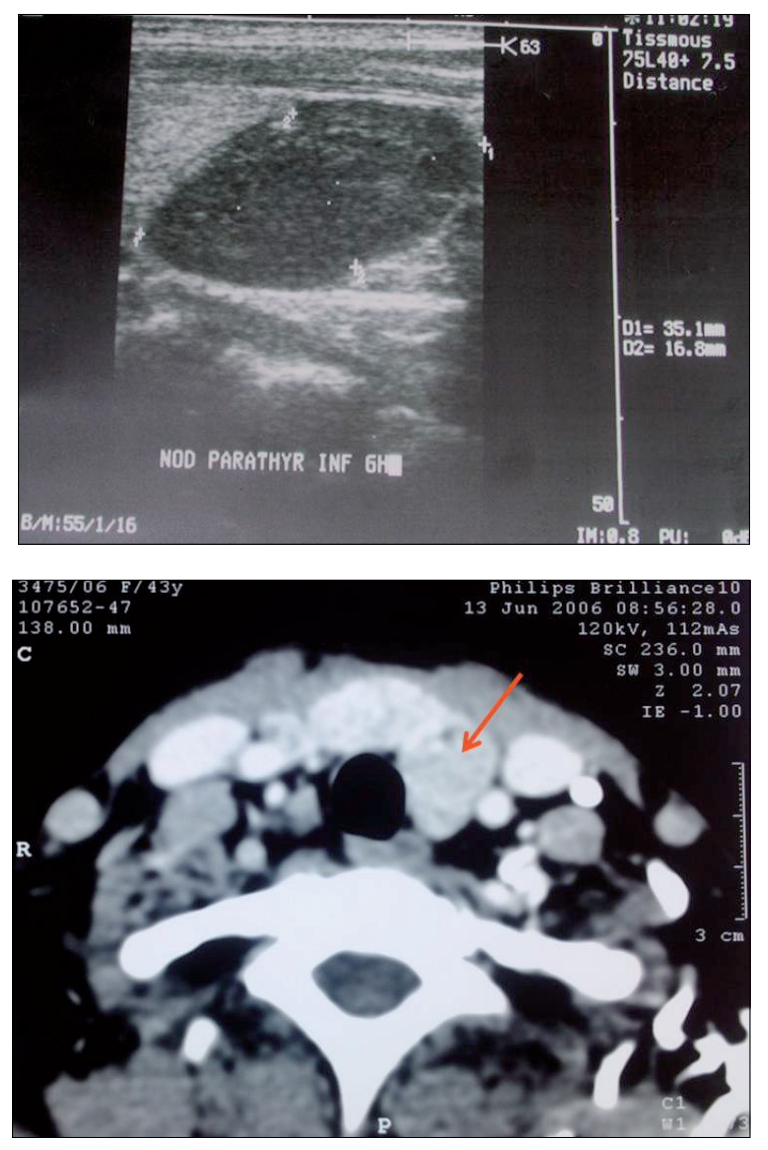

Fig. 4. (A) Ultrasound image showing $3.5 \times 1.7 \mathrm{~cm}$ left parathyroid adenoma. (B) Computed tomography of the neck showing a large mass in the left lower lobe of thyroid gland (arrow).

Fig. 4. (A) Echographie : adénome de la parathyroidde gauche mesurant 3,5 × 1,7 cm. (B) CT-scan de la région cervicale: volumineuse masse dans le lobe inférieur gauche de la glande thyroïde (fléche).
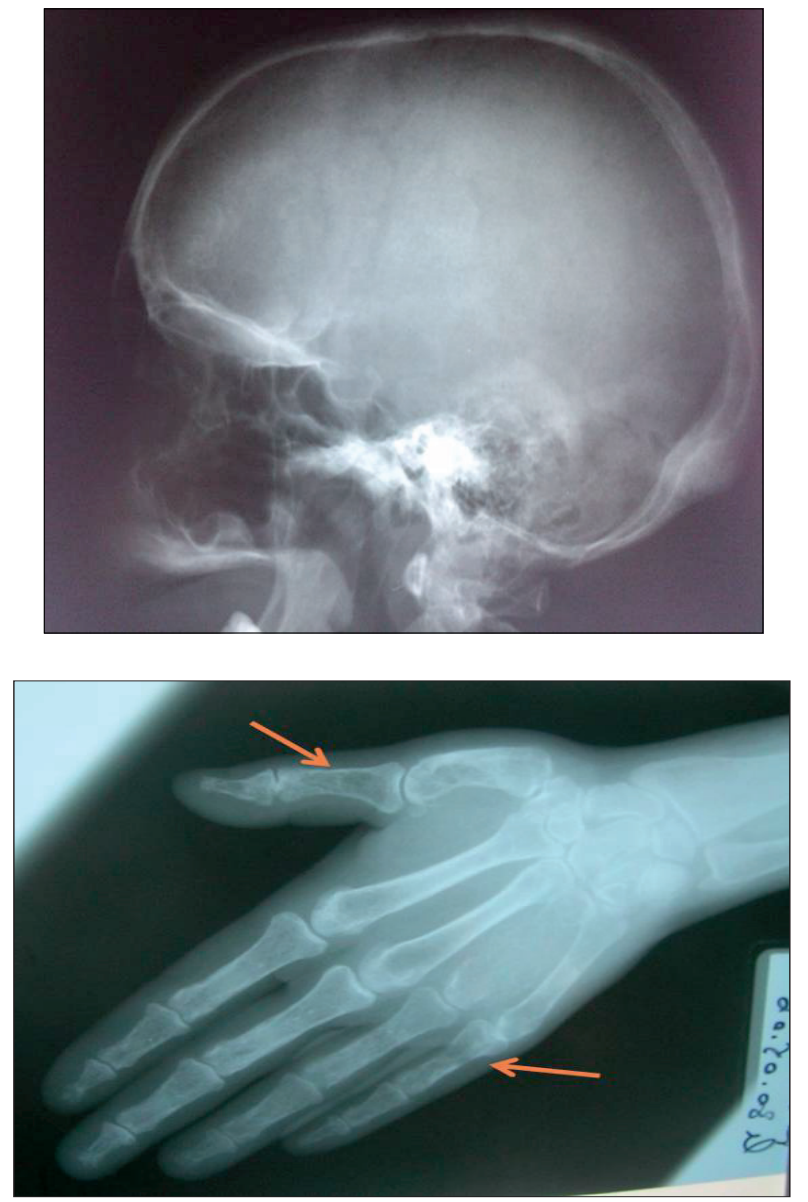

Fig. 5. (A) Lateral view of skull showing "salt and pepper" appearance. (B) Radiograph showing subperiosteal resorption of the phalanges (arrow).

Fig. 5. (A) Crâne de profil : aspect « poivre et sel ». (B) Radiographie montrant une résorption sous-périostée sur les phalanges (fléche).

The treatment consisted of surgical removal of the parathyroid mass. The lesion was histopathologically diagnosed as a parathyroid adenoma (Fig. 6). Medical treatment by biphosphonates was associated. No surgical treatment of the intraoral brown tumor has been achieved. Regression of the swelling was noticed months later.

\section{Discussion}

Primary hyperparathyroidism is more frequently seen in patients over 50 years old, with gender predilection toward females [5]. Classically, it is associated with two major sites of potential complications: the kidneys and the bones [6]. The renal manifestations (nephrolithiasis) are the most common symptom [3]. Bone involvement is the late manifestation [7]. In the past, bones lesions were recognized in $80 \%$ 


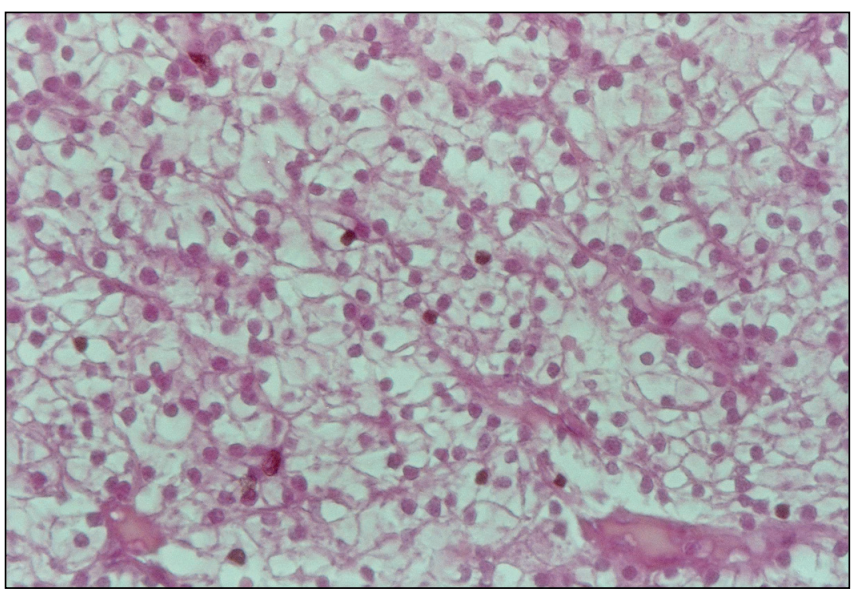

Fig. 6. Microscopic view of the parathyroid tumor: proliferation showing endocrinoide architecture (hematoxylin-eosin, magnification $\times 40$ ).

Fig. 6. Aspect microscopique de la tumeur parathyroiddienne : prolifération ayant une architecture endocrine (hématoxyline-éosine, grossissement $\times 40$ )

to $90 \%$ of patients with primary or secondary hyperparathyroidism [4]. This rate has decreased to less than $5 \%$ of cases because of early diagnosis by routine biochemical screening and successful treatment of the disease $[4,8]$. Classic skeletal lesions are bone resorption, bone cysts, brown tumors and generalized osteopenia [6]. Brown tumors are non neoplastic lesions resulting from abnormal bone metabolism in hyperparathyroidism [9]. They have been described in both primary $(4.5 \%$ of patients with primary hyperparathyroidism) and secondary hyperparathyroidism $(1.5-1.7 \%$ of patient with secondary hyperparathyroidism) as resulting from an imbalance of osteoclastic and osteoblastic activity with bone resorption exceeding the bone formation $[10,11]$. The ribs, clavicles, and pelvis are the sites of predilection of this lesion [11]. Jaw involvement is extremely rare with mandible the most common site than maxillary $[9,11]$.

Clinical symptoms caused by brown tumors depend on their seize and location [11]. They most commonly present as slowly growing, painful masses [11]. Asymptomatic lesions accidentally diagnosed by radiological examination are possible [11]. Radiographically, brown tumors of the jaws present as well-demarcated, monolocular or multilocular osteolytic lesions [4]. As for our patient, other radiographic symptoms related to the primary hyperparathyroidism are usually associated to the brown tumor such as subperiostal bone resorption of phalangeal tufts, loss of lamina dura around the teeth, generalized osteoporosis and "salt and pepper" radiologic appearance of demineralization of the skull $[12,13]$.

Histologically, microscopic findings in brown tumor are non-specific showing classically population of mononuclear stromal cells mixed with multinucleated giant cells, among which recent hemorrhagic infiltrates and hemosiderin deposits are often found [14]. The haemorrhage and hemosiderin give the tumor a brownish color which gives rise to its name $[4,14]$. In our case, histological features alone cannot establish a certain diagnosis because of many giant cell lesions of the jaw bone (central giant cell reparative granuloma, cherubism, aneurysmal bone cyst). A certain diagnosis was confirmed by the endocrinologic status of the patient.

The treatment of hyperparathyroidism is the first step in the management of the brown tumor [14]. There is general consensus that the treatment of primary hyperparathyroidism is parathyroidectomy, but opinions are divided about the management of the bony lesions [5,11-15]. Most authors believe that brown tumor regression and healing are expected after the correction of hyperparathyroidism $[5,14]$. The time necessary for bone regeneration varies from several months in young patients to several years in older patients [5]. In the case reported here, no treatment of the palatal brown tumor has been done. However, several cases of brown tumor that grew after parathyroidectomy or normalization of hyperparathyroidism level have been reported [14]. In these cases, many authors have reported the surgical resection of remaining brown tumor $[4,14]$.

\section{Conclusion}

Despite the improve methods of blood analysis that have led to early diagnosis of this endocrine disorder, there is still the possibility of patients presenting advanced bony lesions of primary hyperparathyroidism. We should therefore investigate all jaws giant cell lesions to exclude primary hyperparathyroidism.

\section{Competing interests: none}

\section{References}

1. Delellis R, Mazzaglia P, Mangray S. Primary hyperparathyroidism: a current perspective. Arch Pathol Lab Med 2008;132:125-62.

2. Jouan A, Zabraniecki L, Vincent V, Poix E, Fournié B. An unusual presentation of primary hyperparathyroidism: severe hypercalcemia and multiple brown tumors. Joint Bone Spine 2008;75:209-11.

3. Fraser WD. Hyperparatyroidism. Lancet 2009;374:145-58.

4. Triantafillidou K, Zouloumis L, Karakinaris G, Kalimeras E, Iordanidis $\mathrm{F}$. Brown tumors of the jaws associated with primary or secondary hyperparathyroidism. A clinical study and review of the literature. Am J Otolaryngol 2006;27:281-6.

5. Daniels JSM. Primary hyperparathyroidism presenting as palatal brown tumor. Oral surg Oral Med Oral Patho Oral Radiol Endod 2004;98:409-13.

6. Guney E, Yigitbasi OG, Bayram F, Ozer V, Canoz 0. Brown tumor of the maxilla associated with primary hyperparathyroidism. Auris Nasus Larynx 2001;28:369-72. 
7. Guimaraes ALS, Marques-Silva L, Gomes CC, Castro WH, Mesquita RA, Gomez RS. Peripheral brown tumour of hyperparathyroidism in oral cavity. Oral Oncol Extra , 2006;42:91-3.

8. Atabek ME, Pirgon 0, Sert A. Extensive brown tumors caused by parathyroid adenoma in adolescent patient. Euro $\mathrm{J}$ Pediatr 2008;167:117-9.

9. Angadi PV, Rekha K, Shetty R. "An exophytic mandibular brown tumor": an unusual presentation of primary hyperparathyroidism. Oral Maxfac Surg 2010;14:67-9.

10. Alhusban M, Baqain ZH. Mandibular brown tumor as the first manifestation of primary hyperparathyroidism: a case report. Saudi Dent J 2011;23:107-9.

11. Proimos E, Chimona TS, Tamiolakis D, Tzanakakis MG, Papadakis CE. Brown tumor of the maxillary sinus in a patient with primary hyperparathyroidism: a case report. J Med Case Reports 2009;3:7495. Available from http://jmedicalcasereports.com/ jmedcalcasereports/article/view/7495.
12. Kar DK, Gupta SK, Agarwal A, Mishra SK. Brown tumor of the palate and mandibule in association with primary hyperparathyroidism. J Oral Maxillofac Surg 2001;59:1352-4.

13. Merz MN, Massich DD, Marsh W, Schuller DE. Hyperparathyroidism presenting as brown tumor of the maxilla. Am J Otolaryngol 2002;23:173-6.

14. Fernandez-Sanroman J, Anton-Badiola JM, Costas-Lopez A. Brown tumor of the mandible as first manifestation of primary hyperparathyroidism: diagnosis and treatment. Med Oral Patol Oral Cir Buccal 2005;10:169-72.

15. Yamazaki H, Ota Y, Aoki T, Karakida K. Brown tumor of the maxilla and mandible: progressive mandibular brown tumor after removal of parathyroid adenoma. J Oral Maxillofac Surg 2003;61:719-22. 